\section{Original Article \\ Dermatology}

Check for updates

\section{OPEN ACCESS}

Received: May 17, 2019

Revised: Aug 6, 2019

Accepted: Sep 4, 2019

*Corresponding author:

Piotr Wilkołek

Sub-Department of Clinical Diagnostics and Veterinary Dermatology, Faculty of Veterinary Medicine, University of Life Sciences in Lublin, Głęboka 30, 20-612 Lublin, Poland.

E-mail: pwilku@poczta.onet.pl

(c) 2019 The Korean Society of Veterinary Science

This is an Open Access article distributed under the terms of the Creative Commons Attribution Non-Commercial License (https:// creativecommons.org/licenses/by-nc/4.0) which permits unrestricted non-commercial use, distribution, and reproduction in any medium, provided the original work is properly cited.

ORCID iDs

Piotr Wilkotek (D)

https://orcid.org/0000-0002-2997-3186

Marcin Szczepanik (D)

https://orcid.org/0000-0002-3650-5356

Wiestaw Sitkowski (D)

https://orcid.org/0000-0001-5340-2626

Beata Rodzik (D)

https://orcid.org/0000-0002-1095-1542

\section{Evaluation of multiple allergen simultaneous (sIgE) testing compared to intradermal testing in the etiological diagnosis of atopic dermatitis in horses}

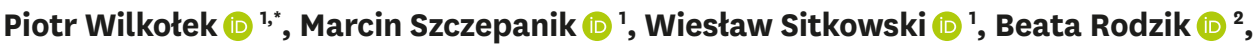 \\ Michat Pluta $\mathbb{D}^{3}{ }^{3}$, Iwona Taszkun (D) ${ }^{1}$, and Marcin Gołyński ${ }^{4}{ }^{4}$ \\ 'Sub-Department of Clinical Diagnostics and Veterinary Dermatology, Faculty of Veterinary Medicine, \\ University of Life Sciences in Lublin, 20-612 Lublin, Poland \\ ${ }^{2}$ Institute of Mathematics, Marie Curie-Skłodowska University, 20-031 Lublin, Poland \\ ${ }^{3}$ Equine Breeding and Management Unit, Department of Biology and Animal Breeding, University of Life \\ Sciences in Lublin, 20-950 Lublin, Poland \\ ${ }^{4}$ Nicolaus Copernicus University in Torun, Faculty of Biological and Veterinary Sciences, 87-100 Torun, Poland
}

\section{ABSTRACT}

Although intradermal testing (IDT) is commonly used in the etiological diagnosis of allergies, in vitro testing for specific $\operatorname{IgE}(\mathrm{sIgE})$ is an attractive alternative. Currently, new laboratory techniques in veterinary allergological practice, including multiple allergen simultaneous tests (MASTs), gradually supersede in vivo tests. Both, serological (sIgE) and IDTs in fourteen atopic Malopolski horses were performed. Correlation and agreement between test results were evaluated. Receiver operating characteristic analysis showed that sIgE to Acarus siro had the best diagnostic performance (Area under the ROC curve $[\mathrm{AUC}]=0.969$ ), followed by Dermatophagoides pteronyssinus (AUC $=0.844)$, Dermatophagoides farinae $(\mathrm{AUC}=0.813$ ) and Tyrophagus putrescentiae $(\mathrm{AUC}=0.803)$. A significant positive correlation between IDT and MAST was found for $A$. siro $\left(\mathrm{r}_{\mathrm{S}}=0.870 ; p=0.00005\right)$, and $D$. farinae $\left(\mathrm{r}_{\mathrm{s}}=0.657 ; p=0.011\right)$. There was significant moderate agreement for 2 of 5 allergens, $A$. siro $(\kappa=0.569)$ and $D$. farinae $(\kappa=0.485)$ in semiquantitative assessment and significant fair to substantial agreement for 3 of 5 allergens, D. pteronyssinus ( $\kappa=0.689)$, A. siro $(\kappa=0.569)$, D. farinae $(\kappa=0.432)$ in dichotomic assessment. Sensitivity ranged from $44 \%$ to $89 \%$, depending on the allergen, while specificity was significantly higher for all allergens in MAST (60\%-100\%); the mean accuracy was $73 \%$ (manufacturer cut-off) and $77.4 \%$ (optimal cut-off) based on the Youden index. Compared with IDT, serological MAST showed good detection performance for $60 \%$ allergen sIgE in dichotomic assessment with substantial diagnostic capability, but careful clinical interpretation is needed for some allergens.

Keywords: Atopy; sIgE; intradermal testing; ROC curve; horses 
Michał Pluta (iD)

https://orcid.org/0000-0003-3069-8828 Iwona Taszkun (iD)

https://orcid.org/0000-0001-8906-5254

Marcin Gotyński iD

https://orcid.org/0000-0001-7182-6334

\section{Funding}

This project was supported by grand DS3/2009-2017 of University of Life Sciences in Lublin, Poland.

Conflict of Interest

The authors declare no conflicts of interest.

Author Contributions

Conceptualization: Wilkotek P, Szczepanik

M; Investigation: Wilkołek P, Szczepanik

M, Pluta M, Gotyński M; Methodology:

Wilkołek P, Rodzik B, Szczepanik M; Project

administration: Wilkołek P; Software: Sitkowski

W, Rodzik B; Visualization: Sitkowski W, Rodzik

B; Writing - original draft: Wilkołek P; Writing -

review \& editing: Rodzik B, Taszkun I.

\section{INTRODUCTION}

The term "atopic dermatitis" (AD) is already fairly common in the equine veterinary literature [1]. The diagnosis of equine $\mathrm{AD}$ is based on a compatible history, clinical signs (recurrent pruritus and/or urticaria) and exclusion of other differential diagnoses, such as ectoparasite infestations, insect bite hypersensitivities and possible adverse food reactions $[2,3]$. Thus far, history and intradermal testing (IDT) are gold standards in etiological diagnosis [4], but serological allergy testing (SAT) has recently been developed to detect specific IgE (sIgE), replacing the more difficult-to-perform in vivo test and have become useful tools for the identification of allergic factors [5]. The reliability of in vitro tests based on the determination of sIgE is of pivotal importance in the selection of relevant allergens for specific immunotherapy [6]. New techniques based on immunoenzymatic multiple allergen simultaneous testing (MAST) are widely used worldwide in the fields of medicine and veterinary medicine, mainly in European and Asian countries, but so far limited data are available from atopic horses. MAST can detects many kinds of specific allergen sIgE at one time with small serum volume, avoiding the cost of horse transportation to place of test performing and a procedure of multiple skin injections [7-11]. Knowledge of the extent of agreement between in vivo and in vitro test becomes particularly important when SIgE is the diagnostic test of choice due to contraindications for IDT.

Storage mites (SMs) and house dust mites (HDMs) are two of the most important allergen sources that cause severe forms of respiratory and skin allergy in horses [12]. The presence of HDMs has been confirmed in the equine environment [13]. The purpose of this study was to evaluate the reliability and diagnostic accuracy of MAST using equine monoclonal antibody mite panel compared with IDT in the etiological diagnosing of AD in horses with mite allergy by assessing the agreement between both test results.

\section{MATERIALS AND METHODS}

\section{Criteria for animal selection}

All tests were performed on fourteen atopic Malopolski horses ( 9 females, 5 males) with an age range of 7-16 years (median age, 11 years) from 2009-2017. Client-owned horses with suspicion of allergy admitted to the Sub-Department of Clinical Diagnostics and Veterinary Dermatology at the University of Life Sciences in Lublin (Poland, referral clinic), for evaluation of recurrent pruritus were included. All horses had clinical symptoms of AD and a history of recurrent perennial pruritus affecting the mane tail, head, thorax area, the dorsal and sometimes the ventral midline. Other causes of skin diseases were ruled out using standard diagnostic techniques (skin scraping, cytology, microbiological culture, elimination diet and appropriate therapy, deworming). Corticosteroid-responsive pruritus were observed in all horses. During the summer horses were kept on pastures with access to a shelter and during the winter in the stables in the same rural area. Prior to all scheduled tests no corticosteroids, antibiotics or antihistamines were discontinued for at least 4 weeks. Local ethical committee approved all investigations involving the use of animals.

\section{Serological tests}

The sIgE was measured from serum samples which were obtained between June and November by venipuncture of the jugular vein and sIgE measurements were performed. The blood $(5 \mathrm{~mL})$ was centrifuged for $10 \mathrm{~min}$ at $4,500 \mathrm{~g}$ and serum samples were kept cool at $4^{\circ} \mathrm{C}$ 
without any freeze-thaw cycles and removed $10 \mathrm{~min}$ before test was performed ( 2 to $10 \mathrm{~h}$ after blood collection). According to the manufacturer's instructions the allergen-specific IgE concentrations were determined in sera using 15 individual allergens, including mite wholebody extract (WBE) (Tyrophagus putrescentiae, Acarus siro, Lepidoglyphus destructor, Dermatophagoides pteronyssinus, Dermatophagoides farinae; Polycheck Allergie NF Horse Panel 20, BioCheck GmbH, Münster, Germany) and five allergen mixtures. The strips were incubated sequentially with horse serum, biotinylated monoclonal anti-equine $\mathrm{IgE}$, anti-anti-equine $\mathrm{IgE}$, avidin-alkaline phosphatase and substrate. The resulting processed strips were dried and scanned on a flatbed scanner. Image analysis software (BioCheck $\mathrm{GmbH}$ ) detected the densities of each band, along with the densities of a series of control bands of graded density and expressed the results in arbitrary units $/ \mathrm{mL}(\mathrm{U} / \mathrm{mL})$. The reactions indicate an allergy classes were interpreted as negative (NR)-class $0(<1 \mathrm{kU} / \mathrm{L})$, mildly positive (MPR)-class $1(1.0-2.0 \mathrm{kU} / \mathrm{L})$, moderately positive (MR)-class $2(2.0-20 \mathrm{kU} / \mathrm{L}$ ) and strongly positive (SR)-class $3(>20 \mathrm{kU} / \mathrm{L}$ ) as per manufacturer's guidelines.

\section{Intradermal tests}

IDTs were performed by one investigator in autumn and winter (between September and December) in unsedated horses in the middle lateral region of the neck. After hair clipping seven injections of $0.1 \mathrm{~mL}$ containing mite WBE were administered intradermally using a 25-G needle- the SMs Tyrophagus putrescentiae, Acarus siro, and Lepidoglyphus destructor and HDMs Dermatophagoides pteronyssinus and Dermatophagoides farinae and other 15 (pollen, insect, molds) were included as test antigens (Agroskin RTU 20, Agrolabo Horse Panel, Scarmagio, Italy). Histamine (1:1,000 w/v) and phosphate buffer were used as a positive and negative control. The diameter and firmness of the wheals were evaluated semiquantitatively at $0.5 \mathrm{~h}$ and $4 \mathrm{~h}$ using a 5-gradual scale: $0=$ no reaction, $+/=$ very flat reaction with a poorly defined contour, $+=$ reaction with slight thickness, $++=$ reaction with evident thickness and $+++=$ reaction with identical thickness as histamine [14].

\section{Statistical analysis}

The diagnostic performance of the tests was assessed using receiver operating characteristic (ROC) curve analysis. The area under curve (AUC), sensitivity (Se), specificity (Sp), positive predictive value (PPV), negative predictive value (NPV) and accuracy (Acc) of MAST were analyzed compared to IDT as the gold standard for each allergen. The optimal cut-off points were determined from the ROC curves, with an equal weight of costs of wrong decisions by the Youden index. Spearman rank correlation test was used in the analysis of associations between IDT and MAST. Cohen's kappa coefficient was used to evaluate multiple levels of agreement between IDT and MAST for dichotomic parameters (DPs) (qualitative, positivenegative) and semiquantitative parameters (grade of the intensity of the test reaction [GIR]): less than 0 , disagreement; $0-0.2$, slight agreement; $0.2-0.4$, fair agreement; 0.4-0.6, moderate agreement; 0.6-0.8, substantial agreement; and 0.8-1, almost perfect agreement. Data analyses were performed using STATISCTICA version 13.3 (TIBCO SOFTWARE Inc., Ireland).

\section{RESULTS}

Using a mean IDT cut-off diameter of at least + and an IgE cut-off value $\geq 1.0 \mathrm{kU} / \mathrm{L}$ for MAST, the most prevalent positive reactions and highest mean values in all performed tests were reported against T. putrescentiae (IDT, 79\%; MAST, 79\%) and D. farinae (IDT, 71\%; MAST, 79\%). 
Table 1. Analysis of IDT results $(+,++$, and +++$)$ and IgE concentrations in sera $(\mathrm{kU} / \mathrm{L})$ showing the number, percentage of positive reactions, mean values and ranges on the MAST in horses with AD

\begin{tabular}{|c|c|c|c|}
\hline \multirow[t]{2}{*}{ Allergen } & \multicolumn{2}{|c|}{ IDT $(n=14):$ No. $(\%)$ PR } & \multirow{2}{*}{$\begin{array}{c}\text { MAST IgE: } \\
\text { No. }(\%) \text { PR, MV (R) }(k U / L)\end{array}$} \\
\hline & Early $(0.5 \mathrm{~h})$ & Late $(4 \mathrm{~h})$ & \\
\hline Tyrophagus putrescentiae & $11(79)$ & $8(57)$ & 11 (79), 5.38 (0.2-15.9) \\
\hline Lepidoglyphus destructor & $9(64)$ & $6(63)$ & $7(50), 1.36(0.2-4.8)$ \\
\hline Acarus siro & $6(43)$ & $5(36)$ & $10(71), 2.1(0.2-6.8)$ \\
\hline Dermatophagoides pteronyssinus & $9(64)$ & $7(50)$ & $9(64), 2.7(0.2-16)$ \\
\hline Dermatophagoides farinae & $10(71)$ & $9(64)$ & 11 (79), $2.44(0.3-7.4)$ \\
\hline
\end{tabular}

IDT, intradermal test; MAST, multiple allergen simultaneous test; $N$, number; PRs, positive reactions; MV, mean values; $R$, ranges; $A D$, atopic dermatitis.

The lowest intensity positive response was observed against $A$. siro (IDT, 43\%) and L. destructor (MAST, 50\%) (Table 1).

ROC analysis showed that sIgE to $A$. siro had the best diagnostic performance (AUC $=0.969$ ), followed by D. pteronyssinus (AUC $=0.844), D$. farinae $(\mathrm{AUC}=0.813)$, T. putrescentiae $(\mathrm{AUC}=0.803)$ and $L$. destructor (AUC $=0.467)$ (Fig. 1). Using the statistical optimal cut-off (based on Youden's index) for sIgE, which was determined from the ROC analysis, a clinical sensitivity and specificity of $86 \%$ and $100 \%$ (A. siro), $73 \%$ and $100 \%$ (T. putrescentiae), $44 \%$ and $60 \%$ (L. destructor) were obtained for SMs and a clinical sensitivity and specificity of $80 \%$ and $75 \%$ (D. farinae) and $89 \%$ and $80 \%$ (D. pteronyssinus) were showed for house mites. The diagnostic accuracy of MAST varied between $50 \%$ for $L$. destructor and $90 \%$ for $A$. siro (Table 2).

A significant positive correlation between IDT and MAST was found for $A$. siro $\left(\mathrm{r}_{\mathrm{s}}=0.870\right.$; $p=0.00005)$ and $D$. farinae $\left(\mathrm{r}_{\mathrm{S}}=0.657 ; p=0.011\right)$. Agreement between IDT and MAST was globally weaker when we graded the intensity of both test reactions than when we used DPs (positive-negative). Significant agreement was obtained for 2 of 5 allergens: $A$. siro $(\kappa=0.569)$

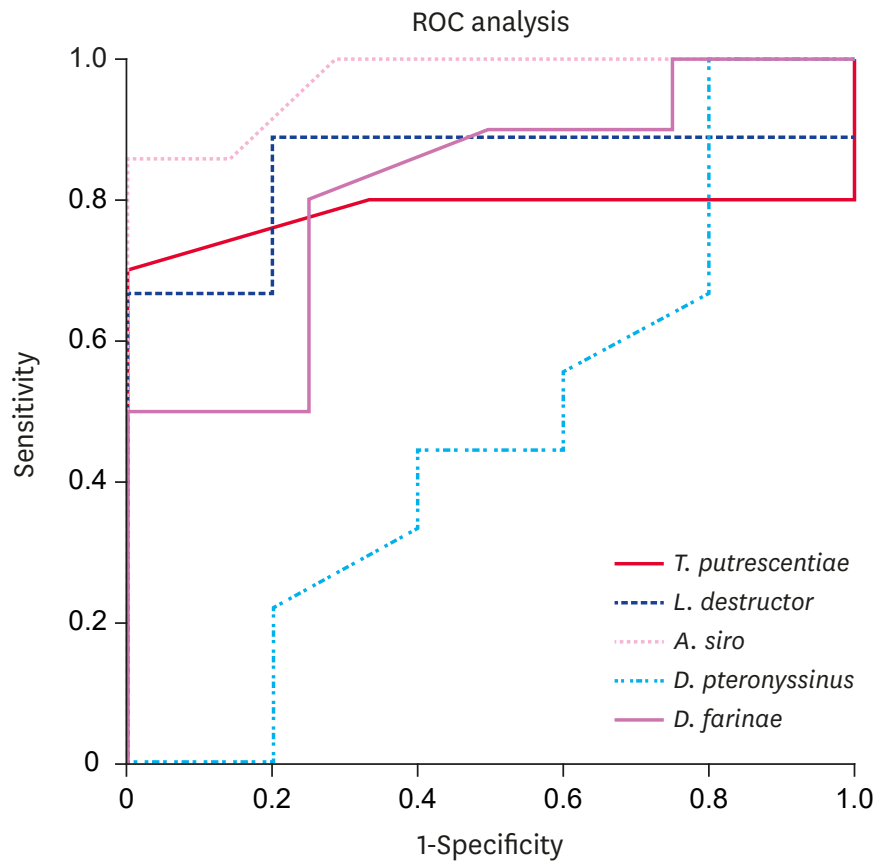

Fig. 1. ROC curves for intradermal test and allergen-specific IgE to mites based on multiple allergen simultaneous test analysis of sera in horses with atopic dermatitis. ROC, receiver operating characteristic. 
Table 2. Diagnostic performance of specific IgE measurement in response to mite allergens calculated from MAST compared to IDT data

\begin{tabular}{|c|c|c|c|c|c|c|c|c|}
\hline Allergen & Cut-off value (kU/L) & Se (\%) & $\mathrm{Sp}(\%)$ & PPV (\%) & NPV (\%) & $\operatorname{Acc}(\%)$ & Youden index & AUC $(95 \% \mathrm{Cl})$ \\
\hline \multirow[t]{2}{*}{ Tyrophagus putrescentiae } & Man $\geq 1,1.4$ & 82 & 33 & 82 & 33 & 71 & 0.152 & $0.803^{*}(0.572-1.0)$ \\
\hline & Opt, 1.7 & 73 & 100 & 100 & 50 & 79 & 0.727 & \\
\hline \multirow[t]{2}{*}{ Lepidoglyphus destructor } & Man $\geq 1,1.3$ & 44 & 60 & 67 & 38 & 50 & -0.156 & $0.467(0.122-0.811)$ \\
\hline & Opt, 1.3 & 44 & 60 & 67 & 38 & 50 & 0.200 & \\
\hline \multirow[t]{2}{*}{ Acarus siro } & Man $\geq 1,1.0$ & 100 & 57 & 70 & 100 & 79 & 0.571 & $0.969^{* * *}(0.889-1.0)$ \\
\hline & Opt, 2.4 & 86 & 100 & 100 & 88 & 93 & 0.857 & \\
\hline \multirow[t]{2}{*}{ Dermatophagoides pteronyssinus } & Man $\geq 1,1.2$ & 89 & 80 & 89 & 80 & 86 & 0.689 & $0.844^{* *}(0.622-1.0)$ \\
\hline & Opt, 1.2 & 89 & 80 & 89 & 80 & 86 & 0.689 & \\
\hline \multirow[t]{2}{*}{ Dermatophagoides farinae } & Man $\geq 1,1.0$ & 90 & 50 & 82 & 67 & 79 & 0.400 & $0.813^{*}(0.565-1.0)$ \\
\hline & Opt, 1.1 & 80 & 75 & 89 & 60 & 79 & 0.550 & \\
\hline
\end{tabular}

Manufacturer and optimal cut-off points were determined using the Youden index.

Man, manufacturer; Opt, optimal; Se, sensitivity; Sp, specificity; PPV, positive predictive value; NPV, negative predictive value; Acc, accuracy; AUC, area under the curve.

Significant values are indicated by ${ }^{*} p<0.05,{ }^{* *} p<0.01,{ }^{* * *} p<0.001$

Table 3. Correlation and agreement analysis between slgE concentrations ( $\mathrm{kU} / \mathrm{L})$ and IDT results

\begin{tabular}{|c|c|c|c|c|c|c|}
\hline \multirow[t]{3}{*}{ Allergen } & \multicolumn{2}{|c|}{ Spearman's rank correlation } & \multicolumn{4}{|c|}{ Cohen's kappa coefficient } \\
\hline & \multirow[t]{2}{*}{$r_{\mathrm{s}}$} & \multirow[t]{2}{*}{$p$ value } & \multicolumn{2}{|c|}{$\kappa$} & \multicolumn{2}{|c|}{$p$ value } \\
\hline & & & GIR & DP & GIR & DP \\
\hline Tyrophagus putrescentiae & 0.152 & 0.11 & 0.059 & 0.152 & 0.379 & 0.285 \\
\hline Lepidoglyphus destructor & 0.185 & 0.527 & 0.089 & -0.043 & 0.318 & 0.564 \\
\hline Acarus siro & $0.870^{* * *}$ & 0.00005 & $0.569^{* * *}$ & $0.571^{* \star}$ & 0.0008 & 0.009 \\
\hline Dermatophagoides pteronyssinus & 0.529 & 0.052 & 0.125 & $0.689^{* *}$ & 0.119 & 0.005 \\
\hline Dermatophagoides farinae & $0.657^{*}$ & 0.011 & $0.485^{* *}$ & $0.432^{*}$ & 0.002 & 0.0497 \\
\hline
\end{tabular}

slgE, specific IgE; IDT, intradermal testing; GIR, grade of the intensity of the reaction; DP, dichotomic parameter.

Significant values are indicated by ${ }^{*} p<0.05,{ }^{* *} p<0.01,{ }^{* \star *} p<0.001$.

and $D$. fariane $(\kappa=0.485)$ for GIR and for 3 of 5 allergens: $D$. pteronyssinus $(\kappa=0.689)$, A. siro $(\kappa=0.571)$, D. fariane $(\kappa=0.432)$ for DP (Table 3$)$.

\section{DISCUSSION}

In this study, we evaluated the performance of a new immune-enzymatic technique for allergen-specific IgE determination in horses with AD. To our knowledge, this is the first study comparing MAST with IDT in horses with storage and domestic mite hypersensitivity. In human medicine, such tests (MAST) have been studied using approved in vivo skin prick tests (SPTs) and in vitro (Phadia, sIgE) methods [15]. Despite current intensive research in the field of immunology, which is promising for further progress in recombinant allergen development [16], most standardized serological tests are based on WBE allergens. Mite recombinant allergens, with the exception of D. pteronyssinus (rDer p 23) and Glycophagus domesticus (rGly d 2), have not yet been presented in serological tests in horses [17]. The use of such recombinants would result in an increase in the specificity of the serological tests and reduce the incidence of false-positive reactions in horses.

In our studies, IDT and MAST showed a high percentage of positive reactions to SMs (mainly T. putrescentiae) and dust mites (D. farinae) what confirms the importance of both allergens in the development of AD in horses. Similar results were observed by Roberts et al. [18], who reported that most positive results in serological tests were obtained for $D$. farinae (24\%) and T. putrescentiae (18\%). The highest agreement for the intensity of the reaction (semiquantitatively) in certain individuals in both tests was for $A$. siro and $D$. farinae, but concordance was not demonstrated statistically for the other mites. However, the intensity of the positive reaction does not necessarily indicate a higher significance of the allergen in the 
etiopathogenesis of the disease. In contrast, comparing dichotomous response categories (positive and negative reactions) showed the highest level of test agreement and indicated that MAST is useful as an alternative to in vivo tests in the diagnosis of causative allergens in horses. In allergology practice, allergen selection for specific immunotherapy is determined by assessment of positive test results, geographical location and seasonality of symptoms, not always based on the strongest reactions in the test [19].

Our findings demonstrate that sIgE to $A$. siro, D. pteronyssinus, D. farinae and T. putrescentiae based on MAST results is good predictor of mite allergy in horses (AUC ranges 0.803-0.969) but to $L$. destructor showed lack of diagnostic value (0.467). Comparisons of serological test results (sIgE in sera) and IDT were previously performed in horses, mainly in the course of recurrent airway obstruction, [18,19], skin hypersensitivity $[20,21]$ and insect hypersensitivity $[3,24]$. Morgan et al. [23] assessed horses with seasonal and perennial symptoms of skin hypersensitivity and urticaria, demonstrating low concordance between IgE and IDT, except for grass allergens. Lorch et al. [22] studied horses with recurrent urticaria, AD, and RAO and reported poor agreement for both tests with mite allergens. The highest agreement was shown in the ELISA test containing monoclonal antibodies in a group of horses with AD. Tahon et al. [20] did not demonstrate the relevance of the mites for the development of RAO in horses, although $50 \%$ of the horses had positive reactions with a commercial ELISA test using the FceRIa against $T$. putrescentiae, with values of $23 \%$ for $D$. farinae and $D$. pteronyssinus and $15 \%$ for $A$. siro. Positive reactions were also observed in healthy control animals. Tilley et al. [21] showed the highest compatibility between serological tests and the prick test for mites (D. farinae) among all groups of allergens. Thus, the sensitivity, specificity and agreement of the different IgE tests varied according to the group of allergens, the type of allergic disease and even individual allergen belonging to the same antigenic group what our study supports. Despite the different test results obtained in comparative studies, mites are a group of major allergens that have the highest percentage of positive responses in in vivo and in vitro tests. Our studies also support the importance of mite allergens in a group of horses with $\mathrm{AD}$ when the main symptom is recurrent pruritus without urticarial, food factors were ruled out as the cause of the observed clinical signs, and the horses responded well to anti-inflammatory doses of glucocorticoids. The probability of sensitivity to mites and positive reactions in such a cohort of animals is very high.

After comparing the values suggested by the manufacturer for MAST and the optimum cutoff values obtained based on the ROC curve and the Youden index, the values overlapped in two cases, but for three allergens, the optimal values of the cut-off points were higher. Similar observations concerning cut-off points have been made in evaluations of diagnostic techniques in medical [25,26] and veterinary studies of recombinant allergens [18], and the ideal equine IDT cut-off threshold values for house and storage allergen dilution concentrations for an immediate type I reaction have been reported [18]. The application of ROC analysis helps in determining a suitable cut-off for each test, with the aim of approaching $100 \%$ certainty of diagnosis [26]. Our results suggest that increasing the cut-off points could improve the accuracy and specificity of MAST.

In our studies, blood was collected during the period of the highest concentration of mite allergens in the environment. These periods correlate with the occurrence of higher mite density in the horse's environment [18]. Scheduling testing during the symptomatic period is crucial for serological tests and reliability of etiological diagnosis for $\mathrm{AD}$ in which we can expect the presence of sIgE in sera. This allows for greater understanding of interdependence between clinical symptoms and results of serological test. However, false-negative results can occur in 
asymptomatic period. IDT was performed in fall and winter during asymptomatic period of the disease [27]. Though, the greatest severity of symptoms associated with allergies to dust mites occurs in summer and autumn, however, symptoms may occur year-round [18].

A critical limitation of this study was the use of IDT as empirically reference method for evaluation of newly developed analyzers. However, IDT is the official reference procedure for allergology practice with good reliability and reproducibility $[14,22]$.

In conclusion, our study confirms the usefulness of MAST using sIgE for storage and domestic mites in horses with AD. The pivotal dust mite allergens in horses are T. putrescentiae and $D$. farinae, which should be taken into consideration for the development of recombinants that could be used in serological tests and specific immunotherapy. High agreement between MAST and IDT applies to positive or negative reactions in atopic horses, and lower concordance occurs in GIR tests. To improve the accuracy of the test, the cut-off point for positive reactions should be increased.

\section{REFERENCES}

1. Stepnik CT, Outerbridge CA, White SD, Kass PH. Equine atopic skin disease and response to allergenspecific immunotherapy: a retrospective study at the University of California-Davis (1991-2008). Vet Dermatol 2012;23:29-35. PUBMED | CROSSREF

2. Loeffler A, Herrick D, Allen S, Littlewood JD. Long-term management of horses with atopic dermatitis in southeastern England: a retrospective questionnaire study of owners' perceptions. Vet Dermatol 2018;29:526-e176. PUBMED | CROSSREF

3. Wilkołek P, Szczepanik M, Sitkowski W, Adamek Ł, Pluta M, Taszkun I, Gołyński M. A comparison of intradermal skin testing and serum insect allergen-specific IgE determination in horses with insect bite hypersensitivity from 2008-2016. J Equine Vet Sci 2019;75:65-68. PUBMED | CROSSREF

4. Popiel J, Cekiera A. Comparison of IgE test results with intradermal skin tests for dust mites and storage mites in atopic dogs. Pol J Vet Sci 2015;18:351-356. PUBMED | CROSSREF

5. Kang MH, Kim HJ, Jang HJ, Park HM. Sensitization rates of causative allergens for dogs with atopic dermatitis: detection of canine allergen-specific IgE. J Vet Sci 2014;15:545-550. PUBMED | CROSSREF

6. Wagner B. Immunoglobulin E and allergy. Equine Vet J 2016;48:13-14. PUBMED | CROSSREF

7. Marti E, Gerber V, Wilson AD, Lavoie JP, Horohov D, Crameri R, Lunn DP, Antczak D, Björnsdóttir S, Björnsdóttir TS, Cunningham F, Dérer M, Frey R, Hamza E, Horin P, Heimann M, Kolm-Stark G, Olafsdóttir G, Ramery E, Russell C, Schaffartzik A, Svansson V, Torsteinsdóttir S, Wagner B. Report of the 3rd Havemeyer workshop on allergic diseases of the Horse, Hólar, Iceland, June 2007. Vet Immunol Immunopathol 2008;126:351-361. PUBMED | CROSSREF

8. Wilkołek P, Sitkowski W, Szczepanik M, Adamek Ł, Pluta M, Taszkun I, Golyński M, Malinowska A. Comparison of serum concentrations of environmental allergen-specific IgE in atopic and healthy (nonatopic) horses. Pol J Vet Sci 2017;20:789-794. PUBMED

9. Han M, Shin S, Park H, Park KU, Park MH, Song EY. Comparison of three multiple allergen simultaneous tests: RIDA allergy screen, MAST optigen, and polycheck allergy. BioMed Res Int 2013;2013:340513. PUBMED | CROSSREF

10. Jang WR, Nahm CH, Kim JH, Lim DH, Jang TY, Moon YS, Kim JJ. Allergen specific IgE measurement with Polycheck Allergy: comparison of three multiple allergen simultaneous tests. Korean J Lab Med 2009;29:465-472.

PUBMED | CROSSREF 
11. Rim JH, Park BG, Kim JH, Kim HS. Comparison and clinical utility evaluation of four multiple allergen simultaneous tests including two newly introduced fully automated analyzers. Pract Lab Med 2016;4:50-61. PUBMED | CROSSREF

12. Mueller RS, Janda J, Jensen-Jarolim E, Rhyner C, Marti E. Allergens in veterinary medicine. Allergy 2016;71:27-35. PUBMED | CROSSREF

13. Wallace JC, Vogelnest LJ. Evaluation of the presence of house dust mites in horse rugs. Vet Dermatol 2010;21:602-607. PUBMED | CROSSREF

14. Lebis C, Bourdeau P, Marzin-Keller F. Intradermal skin tests in equine dermatology: a study of 83 horses. Equine Vet J 2002;34:666-671. PUBMED | CROSSREF

15. Lee JH, Park KH, Kim HS, Kim KW, Sohn MH, Kim CH, Lee JS, Hong CS, Park JW. Specific IgE measurement using AdvanSure ${ }^{\circledR}$ system: comparison of detection performance with ImmunoCAP® system in Korean allergy patients. Clin Chim Acta 2012;413:914-919. PUBMED | CROSSREF

16. Peeters LM, Janssens S, Goddeeris BM, De Keyser K, Wilson AD, Kaufmann C, Schaffartzik A, Marti E, Buys N. Evaluation of an IgE ELISA with Culicoides spp. extracts and recombinant salivary antigens for diagnosis of insect bite hypersensitivity in Warmblood horses. Vet J 2013;198:141-147. PUBMED | CROSSREF

17. Verdon M, Lanz S, Rhyner C, Gerber V, Marti E. Allergen-specific immunoglobulin E in sera of horses affected with insect bite hypersensitivity, severe equine asthma or both conditions. J Vet Intern Med 2019;33:266-274. PUBMED | CROSSREF

18. Roberts HA, Hurcombe SD, Hillier A, Lorch G. Equine intradermal test threshold concentrations for house dust mite and storage mite allergens and identification of stable acari fauna. Vet Dermatol 2014;25:124-134. PUBMED | CROSSREF

19. Radwanski NE, Morris DO, Boston RC, Cerundolo R, Lee KW. Longitudinal evaluation of immunological responses to allergen-specific immunotherapy in horses with IgE associated dermatological disease, a pilot study. Vet Dermatol 2019;30:255-e78. PUBMED | CROSSREF

20. Tahon L, Baselgia S, Gerber V, Doherr MG, Straub R, Robinson NE, Marti E. In vitro allergy tests compared to intradermal testing in horses with recurrent airway obstruction. Vet Immunol Immunopathol 2009;127:85-93. PUBMED | CROSSREF

21. Tilley P, Sales JP, Ferreira MB. Comparison of skin prick tests with in vitro allergy tests in the characterization of horses with recurrent airway obstruction. J Equine Vet Sci 2012;32:719-727. CROSSREF

22. Lorch G, Hillier A, Kwochka KW, Saville WJ, Kohn CW, LeRoy BE. Comparison of immediate intradermal test reactivity with serum IgE quantitation by use of a radioallergosorbent test and two ELISA in horses with and without atopy. J Am Vet Med Assoc 2001;218:1314-1322. PUBMED | CROSSREF

23. Morgan EE, Miller WH Jr, Wagner B. A comparison of intradermal testing and detection of allergenspecific immunoglobulin $\mathrm{E}$ in serum by enzyme-linked immunosorbent assay in horses affected with skin hypersensitivity. Vet Immunol Immunopathol 2007;120:160-167. PUBMED | CROSSREF

24. Ferroglio E, Pregel P, Accossato A, Taricco I, Bollo E, Rossi L, Trisciuoglio A. Equine Culicoides hypersensitivity: evaluation of a skin test and of humoral response. J Vet Med A Physiol Pathol Clin Med 2006;53:30-33. PUBMED | CROSSREF

25. Agarwal R, Aggarwal AN, Garg M, Saikia B, Chakrabarti A. Cut-off values of serum IgE (total and A. fumigatus-specific) and eosinophil count in differentiating allergic bronchopulmonary aspergillosis from asthma. Mycoses 2014;57:659-663. PUBMED | CROSSREF

26. Wongpiyabovorn J, Suratannon N, Boonmee S, Chatchatee P. Comparison of specific IgE detection by immunoblotting and fluorescence enzyme assay with in vivo skin prick test. Asian Pac J Allergy Immunol 2018;36:159-165. PUBMED 
27. Wilkołek PM, Pomorski ZJ, Szczepanik MP, Adamek L, Pluta M, Taszkun I, Gołyński M, Rozwód A, Sitkowski W. Assessment of serum levels of allergen-specific immunoglobulin E in different seasons and breeds in healthy horses. Pol J Vet Sci 2014;17:331-337. PUBMED | CROSSREF 